\title{
FILOSOFIA DA HISTÓRIA, COMBATE E CIVILIZAÇÃO
}

\author{
Vladimir de Oliva Mota ${ }^{1}$
}

Resumo: A partir da fértil interpretação realizada pela Professora Maria das Graças de Souza dos textos de filosofia da história voltairianos e considerando a obra do filósofo francês segundo uma leitura sistemática, o que se pretende aqui é compreender a articulação entre o caráter combativo dos textos de Voltaire com sua noção de Filosofia de História e de Civilização com o fim de apontar a história como um instrumento pedagógico-moral de construção da civilização.

Palavras-chaves: Voltaire - Filosofia da História - Combate - Civilização.

Em 30 de Maio de 1878, em homenagem ao centenário de morte de Voltaire, no Teatro de La Gaité, Victor Hugo proferia o seguinte discurso:

Antes da Revolução, senhores, a estrutura social era isto: em baixo, o povo; acima do povo, a religião representada pelo clero; ao lado da religião, a justiça representada pela magistratura. $\mathrm{E}$, nesse momento da sociedade humana, o que era o povo? A ignorância. O que era a religião? A intolerância. E o que era a justiça? A injustiça.

[...]

Em presença dessa sociedade frívola e lúgubre, Voltaire, sozinho, tendo sob seus olhos todos os poderes reunidos: a corte, a nobreza, as finanças; a força inconsciente: a multidão cega; a pavorosa magistratura: tão pesada aos indivíduos, tão dócil ao chefe, esmagando e bajulando, de joelhos sobre o povo diante do rei; o clero sinistramente misturado de hipocrisia e fanatismo; Voltaire, sozinho, eu o repito, declara guerra a essa coalizão de todas as iniquidades sociais, a esse mundo enorme e terrível, e aceita a batalha. Qual é sua arma? Aquela que possui a leveza do vento e a força do raio: uma pena. $[\ldots]$

\footnotetext{
${ }^{1}$ Doutor em Filosofia pela Universidade de São Paulo (USP) e Professor do Departamento de Artes Visuais e Design e do Programa de Pós-Graduação em Filosofia da Universidade Federal de Sergipe (DAVD/UFS).
} 
Senhores, há entre dois servidores da humanidade, que apareceram a um intervalo de mil e oitocentos anos, uma relação misteriosa. Combater farisaísmo, desmascarar a impostura, colocar por terra as tiranias, as usurpações, os preconceitos, as mentiras, as superstições, [...] substituir o falso pelo verdadeiro, atacar a magistratura feroz, atacar o sacerdote sanguinário, tomar o chicote e expulsar os vendedores do santuário, reclamar a herança dos deserdados, proteger os fracos, os pobres, os adoentados, os abatidos, lutar pelos perseguidos e oprimidos; é a guerra de Jesus Cristo. E qual é o homem que travou essa guerra? Voltaire. [...] Dizemo-lo com um sentimento de respeito profundo: Jesus chorou, Voltaire sorriu; é dessa lágrima divina e desse sorriso humano que é feita a doçura da civilização atual².

É conhecida a face satírica, irônica e polêmica da obra de Voltaire, assim como o seu objetivo de fazer uso de sua agressiva pena no combate em nome de uma ideia de civilização. Roland Mortier explica que a escrita voltairiana “[...] está ligada à atualidade por uma rede cerrada de alusões e de referências que fazem dela uma obra profundamente engajada na luta mais ampla por uma reforma da sociedade." 3 René Pomeau diz que a ação de Voltaire agitou todo o seu século, "ela demonstrou o poder explosivo da escrita" ". Alguns consideram como Victor Hugo - que Voltaire obteve êxito em seu projeto e ajudou a mudar a face do mundo, provocando polêmica e riso. ${ }^{5}$ É com esse propósito que ele escreveu, para o combate, para agir, pois, como dizia, o homem nasceu para a ação ${ }^{6}$ e a sua ação é o combate por parágrafos.

A partir da fértil interpretação realizada pela Profa ${ }^{a}$ Maria das Graças de Souza dos textos de filosofia da história voltairianos e considerando a obra do filósofo francês segundo uma leitura sistemática, o que se pretende aqui é compreender a articulação entre o caráter combativo dos textos de Voltaire com sua noção de Filosofia de História e de Civilização com o fim de apontar a história como um instrumento pedagógico-moral de construção da civilização.

Para tal, antes, faz-se necessário adotar o seguinte pressuposto: há um nexo que associa as ideias que fundamentam o pensamento filosófico voltairiano e ao caráter combativo da expressão desse pensamento. Isto é: a leitura sistemática da obra prodigiosamente vasta e igualmente variada de Voltaire revela dois aspectos indeléveis: por um lado, mostra um autor de uma produção teórica estruturada, seus argumentos estão sobre algumas bases que se pretendem sólidas e inalteradas; elaborando, assim, um pensamento consistente. Por outro lado, o caráter combativo dos seus textos, ao passo que articula os vários gêneros de escrita praticados pelo filósofo - cujo critério de escolha é o que melhor se adequaria às circunstâncias da luta -, é consequência daquele pensamento consistente.

\footnotetext{
2 Tradução de Vladimir de Oliva Mota. Extratos do texto extraído de: HUGO, Discours prononcé pour le centenaire de Voltaire.

3 MORTIER, "Les formes de la satire chez Voltaire". In: Le coeur et la raison, p. 117.

4 POMEAU, La religion de Voltaire, p. 360.

${ }^{5}$ ROMANO, "Voltaire e a sátira". In: O caldeirão de Medeia, p. 177.

${ }^{6}$ Cf.: VOLTAIRE, "Lettres philosophiques". In: Mélanges, p. 119.
} 
A sistematicidade requerida à leitura da obra voltairiana, que possibilita a apreensão da consistência de seu pensamento e efeito dessa no caráter combativo de seus textos, pode ser assim orientada: a leitura "em bloco" e a busca por textos em momentos distintos da vida do filósofo possibilitam identificar o que permanece, a essência do seu pensamento e a articulação das suas ideias, pois além do fato de que algumas posições do pensamento voltairiano não se alterarem, elas são possíveis de serem extraídas de seus textos, não importando o gênero que lhes serve de meio e as circunstâncias múltiplas do combate nas quais se engajam. Soma-se a isso o fato de que Voltaire, estrategicamente, repete-se, o que fortalece ainda mais a ideia dessa permanência. A leitura em bloco e em diferentes períodos da obra voltairiana permite desvelar um nexo interno em seus textos assim como lança luz sobre o seu uso. Ao não observar essas exigências de leitura, corre-se o risco de fazer de Voltaire o que se desejar.

Tendo a razão como guia, como princípio supremo de organização da vida, o pensamento das Luzes pretende-se reformador dos espíritos. Persuadido dessa tarefa, Voltaire utiliza todo o seu talento literário, pois acredita que as letras não estão dissociadas da filosofia. Escreve ele ao abade d'Olivier, em 20 de outubro de 1738:

Será a verdade tão desgraçada que não possa suportar os ornamentos? A arte de bem pensar, de falar com eloquência, de sentir vigorosamente e de assim se exprimir, seria tudo isso inimigo da filosofia? Não, sem dúvida esta é uma forma bárbara de pensar?

A barbárie do pensamento se traduz, para Voltaire, na dissociação desse pensamento com a vida, camuflada de uma linguagem rebuscada de um tecnicismo empolado e estéril, pois desassociado da experiência: o mundo de Pangloss não corresponde ao real, consequência de uma filosofia de letrados apartados do convívio social.

O benefício prático que um pensamento filosófico viabiliza é o critério de valor de uma filosofia no século XVIII francês; nas palavras de Paul Hazard: "Tal como se reconhece uma árvore pelos frutos que dá, o valor de uma filosofia mede-se pelos benefícios de sua ação" 8 . E Voltaire é um homem das Luzes, sem dúvida. E o que isso significa? Significa que Voltaire é um símbolo de uma época em que a filosofia estava incumbida de intervir nos negócios do mundo. Recusando se enclausurar no silêncio do seu gabinete e na poeira dos seus livros, a filosofia era atividade de quem "desceu à arena", como disse o próprio filósofo, ou de quem foi até o "covil das feras", na expressão de Diderot. Voltaire faz uma filosofia cuja história examinou por toda a vida - não só vinculada ao mundo, ao homem, à experiência, enfim, à vida, mas uma filosofia da qual o combate por esse mundo é um elemento constitutivo. Ele fez da pena uma arma de luta contra a coalizão de todas as iniquidades sociais, que sintetiza sob o adjetivo: a infame (l'infâme). A infame deve ser esmagada para que o bem-estar social prevaleça, para que a felicidade possível neste mundo seja viabilizada; assim, Voltaire escreve para melhorar a vida social, excitando sentimentos e reflexões. Com esse propósito, pretende a tão difícil união entre teoria e prática, razão e

\footnotetext{
${ }^{7}$ VOLTAIRE, "Correspondance". In: Oeuvres complètes de Voltaire. L'édition Moland (CD-ROM).
}

${ }^{8}$ HAZARD, O pensamento europeu no século XVIII, p. 155. 
liberdade. O combate na obra voltairiana apresenta-se como um elemento constitutivo de sua filosofia porque, por um lado, Voltaire não abandona a reflexão para dedicar-se ao combate, como foi dito, este é a extensão daquela. Por outro lado, o combate é um elemento constitutivo de sua filosofia porque ele é responsável por unir sua obra num todo coerente: seus textos, apresentados sob uma multiplicidade de formas e temas, pois necessita adequarse às circunstâncias para produzir, com mais eficiência, o efeito desejado, tem sempre um mesmo fim, a saber: o combate pelo aperfeiçoamento dos costumes, que o esclarecimento possibilita.

Pronunciar o nome de Voltaire é despertar o espírito de partido, é interminável a controvérsia acerca de sua filosofia: uns nada lhe atribuem, outros fecham os olhos aos seus defeitos e todos, para cúmulo da desavença, recorrem a passagens do próprio Voltaire para sustentar posições antagônicas aos seu respeito. A Filosofia de História é um dos temas desse desentendimento irreconciliável entre os comentadores. Não se pretende aqui esgotar o debate, mas tão somente seguir uma via aberta à possível compreensão desse tema.

Por exemplo: referindo-se à crítica de Voltaire, entre outras, à Teologia da História, Bertrand Binoche afirma que "[...] a coerência da filosofia voltairiana da história é essencialmente negativa" 9 . Para demonstrar seu partido, Binoche recorre a uma passagem de uma correspondência do filósofo a d'Alembert, de 05 de Abril de 1765: "Meus filósofos são homens de bem que não têm princípios fixos sobre a natureza das coisas, que não sabem o que é, mas que sabem muito bem o que não é" ${ }^{10}$. E para fundamentar seu partido, Binoche cita Espinosa: "as coisas que concordam só na negação, por outras palavras, naquilo que não tem, não concordam na realidade em nada" ${ }^{11}$. Caso a premissa de que a coerência da filosofia voltairiana da história é essencialmente negativa estivesse correta, essa análise seria irretocável.

Esquivando-se aqui da explicação sobre a impossibilidade, no pensamento filosófico de Voltaire, do estabelecimento de "princípios fixos sobre a natureza das coisas" ${ }^{12}$, vale ser observado o seguinte: a data da correspondência citada por Binoche, 1765, é a mesma da primeira publicação da obra Filosofia da história, única utilizada como referência na sua análise. Isso indica que a discussão foi feita considerando como referência somente aquela obra e aquele período, isolando-os do corpus voltairiano. Em 1994, René Pomeau, na obra La religion de Voltaire, alertara para os riscos de se analisar Voltaire por "amostragens", isto é, considerando um período específico e/ou passagens de textos do filósofo sem levar em consideração o conjunto de sua obra. A consequência do equívoco de analisar Voltaire por amostragens, assegura Pomeau, são as intermináveis perspectivas criadas - em sua maioria, divergentes - acerca do pensamento voltairiano ${ }^{13}$.

Com mais atenção às exigências metodológicas à leitura de obras do Iluminismo francês, de um modo geral, e da obra voltairiana, em particular, considerando um período mais vasto e muitos e importantes textos de Voltaire, a Prof ${ }^{a}$. Maria das Graças de Souza

9 BINOCHE, Les trois sources des philosophies de l'bistoire (1764-1798), p. 42.

10 VOLTAIRE, "Correspondance". In: Oewures complètes de Voltaire. L'édition Moland (CD-ROM).

${ }^{11}$ ESPINOSA, Ética, p. 363.

12 Pois tal explicação fora já realizada. A esse respeito ver: MOTA, Voltaire e a crítica à metafísica: um ensaio introdutório.

${ }^{13}$ POMEAU, La religion de Voltaire, p. 15. 
abre um fértil caminho à compreensão da Filosofia da História em Voltaire em Ilustração e História. Ela explica que aquela expressão significa:

de um lado, uma maneira de conceber o processo histórico, mas, de outro, significa também o modo de reconstruir esse processo para o leitor do presente. $^{14}$

Não é correto afirmar que a coerência da filosofia voltairiana da história é essencialmente negativa. Ao contrário, ela implica - desde que seja considerada a sua obra e não um texto e um período isolados - um ordenamento dos fatos históricos em função de uma direção a ser tomada pela história, a civilização. Essa perspectiva, além de exigir uma cadeia de noções que vai desde a ideia de ação livre até sua complexa relação com a de uma Providência Geral $^{15}$, passando pela ideia de probabilidade das verdades históricas ${ }^{16}$, faz do pensamento voltairiano sobre a história, ainda segundo a Prof ${ }^{a}$. Maria das Graças de Souza, particular e original:

embora guarde da concepção linear da história a ideia de progresso e da tradição cíclica a ideia do retorno, a concepção voltairiana entendida à luz da doutrina do grande século ${ }^{17}$, rejeita, da primeira, a ideia de um telos necessário em direção ao qual caminharia a humanidade e, da segunda, a noção de retorno do mesmo, constituindo assim uma visão da história particular e original $^{18}$.

O assunto da investigação histórica de Voltaire é a civilização. A história é a trajetória da civilização. Mas o que significa aqui civilização? De acordo com, mais uma vez, a Profa . Maria das Graças de Souza, civilização significa “[...] o conjunto dos desenvolvimentos

${ }^{14}$ SOUZA, História e Ilustração: o pensamento sobre a bistória no Iluminismo francês, p. 118.

15 A esse respeito ver: MOTA, "Providência e liberdade em Voltaire: uma homenagem à Professora Maria das Graças de Souza”. In: Quadranti, Rivista Internazionale di Filosofia Contemporanea.

16 Acerca da aplicação do probabilismo às verdades históricas, ver: SAGER, "Retour sur le probabilisme voltairien". In: Cahier Voltaire. O probabilismo comanda a visão voltairiana da história; assim, a crítica à Teologia da história funda-se nesse exame probabilístico: "Os primeiros fundamentos da história são as narrativas dos pais aos filhos, transmitidas em seguida de uma geração a outra; elas não são mais do que prováveis em sua origem, quando não se chocam como senso comum, e perdem um grau de probabilidade a cada geração. Com o tempo, a fábula cresce e a verdade se perde; por esse motive, todas as origens dos povos são absurdas". (VOLTAIRE, "Questions sur l'Encyclopédie". In: Oeuvres complètes de Voltaire. L'édition Moland (CD-ROM)).

${ }^{17}$ Explica a Profa. Maria das Graças de Souza: "A expressão 'grande século', como se sabe, é de Voltaire, que com ele pretendia assinalar momentos de apogeu do espírito humano, e integra a ideia de retornos periódicos de épocas de perfeição. Assim, segundo Voltaire, a humanidade teria vivido quatro grandes séculos: o de Felipe e Alexandre, na Grécia, o de Augusto, em Roma, o Renascimento, na Itália, e por fim, na França, o século de Luís XIV. Entre essas épocas, o espírito humano viveu períodos de estagnação ou mesmo de retorno à barbárie. O critério que permite determinar o que é um grande século é de caráter cultural e intelectual". (SOUZA, História e Ilustração: o pensamento sobre a bistória no Iluminismo francês, p. 111)

${ }^{18}$ SOUZA, História e Ilustração: o pensamento sobre a história no Iluminismo francês, p. 113. 
produzidos pelo homem nas artes, nas ciências, nas técnicas, e, além disso, das transformações espirituais e morais que acompanham esse desenvolvimento"19. Em uma palavra: "[...] a realização, nas sociedades humanas, dos valores estabelecidos pela razão"20. Não obstante a civilização ser a direção a ser seguida pela história, como foi dito, ela não é um telos necessário, há sempre o risco da recaída na barbárie, isto é, tudo aquilo que ameaça a vida - as prisões forçadas, as condenações sem defesa, a tortura, os confinamentos em mosteiros, os assassinatos, os suplícios, os duelos, as guerras... - e tudo aquilo que afeta o espírito de liberdade - as fraudes religiosas ou políticas, o abuso do poder político e religioso, a perseguição por delito de opinião, a censura, a superstição, a ignorância, a manutenção de preconceitos do passado, a intolerância religiosa ou política... A recaída na barbárie pode sempre ocorrer e impedir esse mal e contribuir para a consecução dos fins estabelecidos pela razão é dever da ação dos homens e, sobretudo, dos filósofos.

Por essa razão, a história se faz útil na pena de Voltaire. No verbete "Histoire" das Questions sur l'Encyclopédie, o autor pergunta e aponta para a utilidade da história: "Qual seria a história útil? A que nos ensina nossos deveres e nossos direitos, sem parecer que pretende ensiná-los"21. Isso significa que os textos sobre história são utilizados como meios para atingir um determinado fim. E que fim é esse? Voltaire o expõe ainda no referido verbete:

Essa vantagem consiste sobretudo na comparação que um estadista, um cidadão pode fazer das leis e costumes estrangeiros com os do seu país: é o que estimula a emulação das nações modernas nas artes, na agricultura, no comércio.

Os grandes erros do passado servem muito e de todas as maneiras; nunca os crimes e as desgraças seriam suficientemente recordados. Digam o que quiserem, mas se pode prevenir aqueles e estas. [...] O exemplo produz grande efeito nos espíritos $[\ldots]^{22}$.

Voltaire segue afirmando que é necessário ter diante dos olhos os males causados pelos maus; se não tornarem esses conhecimentos familiares aos jovens: "As calamidades desses tempos de ignorância renasceriam infalivelmente, por não se tomar nenhuma precaução para preveni-las"23. E Voltaire conclui dramaticamente: "Aniquilem o estudo da história e verão dias de São Bartolomeu [...]"24.

Portanto, a utilidade da história é, em certo aspecto, instruir os homens, contribuir para o aperfeiçoamento dos seus costumes. O historiador filósofo deve fazer uso da razão

\footnotetext{
${ }^{19}$ Idem, p. 114.

${ }^{20}$ Idem, Ibidem.

${ }^{21}$ VOLTAIRE, “Questions sur l'Encyclopédie. In: Oeuvres complètes de Voltaire”. L'édition Moland (CD-ROM).

22 Idem.

${ }^{23}$ Idem.

${ }^{24}$ Em 24 de agosto de 1572, ocorre o massacre conhecido como a Noite de São Bartolomeu - dos protestastes em Paris e nas províncias por ordem do rei Carlos IX, encorajado por sua mãe Catarina de Médicis.
} 
muito mais do que da memória porque a utilidade da reconstrução do passado é ensinar pelo exemplo, ela deverá contribuir para demolir a barbárie e edificar a civilização. A leitura da história, segundo Voltaire, fornece armas, exemplo e entusiasmo na investida da razão contra a infâmia. Pode-se dizer, por conseguinte, que a Filosofia da História de Voltaire, em determinado aspecto, não pretende tão somente reconstituir os fatos, mas ela é também marcada por uma preocupação moral e pedagógica, de modo a se tornar um instrumento de combate a favor, na expressão de Victor Hugo, da doçura da civilização.

\section{PHILOSOPHY OF HISTORY, COMBAT AND CIVILIZATION}

Abstract: From professor Maria das Graças de Souza's fertile interpretation of voltarian philosophy of history texts and considering the work of this French philosopher according to a systematic reading, what is intended here is to comprehend the articulation between the feisty character of Voltaire's texts and his philosophy of history and civilization thought, aiming to indicate history as a pedagogical-moral instrument to establish civilization.

Keywords: Voltaire - Philosophy of History - Feisty - Civilization.

\section{REFERÊNCIAS BIBLIOGRÁFICAS}

BINOCHE, Bertrand. Les trois sources des philosophies de l'bistoire (1764-1798). Paris: PUL, 2008.

ESPINOSA, Baruch de. Ética. Tradução Antônio Simões. São Paulo: Nova Cultural, 1997. (Coleção “Os Pensadores”).

HAZARD, Paul. O pensamento europeu no século XVIII. Tradução Carlos Grifo Babo. Lisboa: Presença, 1989.

HUGO, Victor. Discours prononcé pour le centenaire de Voltaire. 1878. Disponível em $<<$ www.voltaire-integral.com>>. Acessado em 17 de agosto de 2007.

MORTIER, Roland. "Les formes de la satire chez Voltaire". In: Le coeur et la raison. Paris: Voltaire Foundation, 1990.

MOTA, Vladimir de Oliva. "Providência e liberdade em Voltaire: uma homenagem à Professora Maria das Graças de Souza". In: Quadranti, Rivista Internazionale di Filosofia Contemporanea, vol. III, $\mathrm{n}^{\circ}$ 1-2, 2015. Disponível em https://www.rivistaquadranti.eu. Acessado em 06 de maio de 2020.

MOTA, Vladimir de Oliva. Voltaire e a crítica à metafísica: um ensaio introdutório. São Cristóvão: Editora da UFS; Aracaju, Fundação Oviedo Teixeira, 2010.

POMEAU, René. La religion de Voltaire. Paris: Nizet, 1995.

ROMANO, Roberto. Voltaire e a sátira. In: O caldeirão de Medeia. São Paulo: Perspectiva, 2001. 
SAGER, Alain. "Retour sur le probabilisme voltairien". In: Cabier Voltaire. No 13, FerneyVoltaire, Sept., 2014.

SOUZA, Maria das Graças de. "Voltaire e a revolução francesa". In: RIBEIRO, Renato Janine (Org.). 1789 Sombra e Luæes. São Paulo: Serviço de Artes Gráficas - FFLCH/USP, 1992.

SOUZA, Maria das Graças de. "Voltaire e Rousseau: metafísica e história". In: MENEZES, Edmilson (Org.) História e providência: Bossuet, Vico e Rousseau. Ilhéus: Editus, 2006.

SOUZA, Maria das Graças de. História e Ilustração: o pensamento sobre a bistória no Iluminismo francês. São Paulo: Discurso, 2001.

SOUZA, Maria das Graças de. Voltaire e o materialismo do século XVIII. Dissertação (Mestrado em Filosofia) - Faculdade de Filosofia Letras e Ciências Humanas (FFLCH), Departamento de Filosofia, Universidade de São Paulo (USP), São Paulo, 1983.

SOUZA, Maria das Graças de. Voltaire: a razãa militante. São Paulo: Moderna, 1993 (Coleção "Logos").

VOLTAIRE. Mélanges. Paris: Gallimard, 1997 (Bibliothèque de la Pléiade).

VOLTAIRE. Oeuvres complètes de Voltaire. L'édition Moland. Paris: Garnier, 1875. VOLTAIRE-INTEGRAL. CD-ROM, 1999-2005.

VOLTAIRE. Oeuvres historiques. Paris: Gallimard, 2000 (Bibliothèque de la Pléiade).

VOLTAIRE. "Providência". Tradução Vladimir de Oliva Mota. In: Philosophica: Revista de Filosofia da História e Modernidade. São Cristóvão, No 3, março, 2002. 